\title{
Lexical Access in Bulgarian: Nouns and Adjectives with and without Floating Vowels*
}

\section{Pier Marco Bertinetto}

Scuola Normale Superiore

Piazza dei Cavalieri 7. I-56126 Pisa (Italy)

bertinetto@sns.it

\section{Georgi Jetchev}

University of Sofia St. Kliment Ohridski. Department of Romance Philology

Bul. Tsar Osvoboditel 15. 1504 Sofia (Bulgaria)

jetchev@fcml.uni-sofia.bg

\begin{abstract}
The main goal of the experiments described in this paper was to compare the behavior of Bulgarian words with vs. without «vowel/ Ø» alternation. The Ø-form may for instance be observed, within the relevant word paradigms, in noun plurals, in adjectives' gender and plural inflections, and in derived nouns. The materials in experiment 1 consisted of six sets of frequency controlled Bulgarian words, contrasting with respect to the following factors: Alternation (sets A1, B1, C1 with alternation vs. A2, B2, C2 without alternation), Morphology (set A with plural formation, an inflectional process, vs. set $\mathrm{C}$ with abstract noun formation, a derivational process), and Stress pattern (set A with first syllable stress vs. set B with second syllable stress). The experimental paradigm was based on repetition priming with visual-input lexical decision. Alternation had a clear effect on the lexical decision time, while Morphology (in the specific manifestation of this parameter) was virtually ineffective and Stress had a minor effect. The materials in experiment 2 consisted of two sets of adjectives contrasting with respect to Alternation (D1 vs. D2), presented in three forms: base-form, inflected (plural) and derived (the corresponding abstract noun). The results of experiment 2 substantially replicate those of experiment 1 . The converging results of experiments 1 and 2 offer themselves to a relatively straightforward interpretation. The Bulgarian participants showed a sharp inclination towards full listing, i.e. direct access, of the morphologically modified forms (both inflected and derived) of morphophonologically complex, thus opaque, alternating words. By contrast, the morphologically modified forms of non-alternating, transparent words were clearly processed compositionally. As for the contrast inflection/derivation, although the specific instantiation of this opposition did not prove to directly yield a statistical difference, its interplay with the morphophonological complication implied by the process of vowel/ $\varnothing$ alternation produced a relatively clear effect in terms of lexical decision speed. Finally, the combination of vowel alternation and second syllable stress, involving replacement of the stressed vowel in morphologically modified forms, seemed to enhance the intimations of direct access.
\end{abstract}

Key words: alternation, floating vowels, lexical access, morphology, phonology, psycholinguistics; Bulgarian.

* We wish to thank Maddalena Agonigi who assisted us with the experimental software and the statistical analyses, as well as Cristina Burani and Alessandro Laudanna for useful comments and guidance in the preliminary phases of this research. 


\section{Table of Contents}
1. Introduction
Appendix A
2. Experiment 1
Appendix B
3. Experiment 2
References

4. General discussion and conclusion

à Georges Boulakia, en amitié

\section{Introduction}

The growing body of psycholinguistic research concerning lexical access is one of the major sources of information on the debated problem of compositionality vs. non-compositionality in the processing of morphologically complex forms. The compositional approach involves access to the individual morphemes that constitute the intended form, in order to check for root-plus-affix compatibility. In order to perform this checking, the cognitive system must be endowed with the appropriate rule machinery, in order to generate all and only the correct words. The noncompositional view involves instead direct access to the intended form, considered as permanently activated in the mental lexicon. Although both approaches have been advocated in their extreme versions, most scholars would now agree that both routes of internal lexicon access are viable, the difference lying in the particular subset of the lexicon involved. In a review of this topic, Bertinetto (1994) provided the following putative summary:

a) Derived forms are less likely to be rule-governed than inflected forms.

b) Non-productive forms are less likely to be rule-governed than productive forms.

c) Morphotactically and semantically opaque forms are unlikely to be rulegoverned, whereas transparent forms may be.

d) Irregular forms are unlikely to be rule-governed, whereas regular forms may be.

e) Non-frequent forms are more likely to be rule-governed than frequent forms.

This pattern becomes even more complicated as one considers the single factors' interplay. As far as derivation is considered, for instance, one should distinguish between idiosyncratic and non-productive formations vis-à-vis totally transparent and productive ones, for the latter are obviously more liable to rule-generation than the former. In addition, one should also take into account typological inclinations. Derived forms of agglutinating languages are more likely to be rule-governed than the corresponding forms of inflectional languages. The number of possible formations in the former languages is in fact so high as to make it extremely unlikely that all such forms are permanently stored in the mental lexicon (specially considering the tendential regularity of agglutinating processes). 
Given this situation, it is not possible to assess the problem once and forever. The task rather consists of carefully accumulating diverse pieces of evidence, from as many languages as possible and from as many subsets of the lexicon as possible, in order to gradually build an overall picture. The present paper presents some evidence from Bulgarian, a language not often explored in experimental psycholinguistic. The special interest of Bulgarian lies in the fact that this language, as is typical of Slavic languages, presents «vowel/Ø» alternations in a number of morphologically complex forms. Words exhibiting this sort of alternation are said to contain «floating» vowels, historically connected with the distribution of high vowels (called «yers» in historical grammars of Slavic languages), which were subsequently lost, causing a number of language-specific morphophonological consequences. ${ }^{1}$ In Bulgarian, the floater may appear as either /e/ or schwa (the latter transcribed as $<\mathrm{a}>$ in transliterated Bulgarian orthography), although these vowels do not necessarily imply alternation. The corresponding $\emptyset$-form may typically be observed, in the relevant word paradigms, in the noun plurals, in adjectives' gender and plural inflection, and in derived nouns. In section 2 we shall provide examples of these alternation types (see Jetchev forthcoming for a detailed formal account of this phenomenon, and Manova and Dressler 2001 for a thorough analysis of Bulgarian nouns' inflectional paradigms within a dynamic morphology approach).

The presence of this mechanism injects into the Bulgarian lexicon a certain amount of morphophonological complexity, worth of experimental investigation. These alternations may lend themselves as rule-governed processes, for they do not imply an entirely irregular behavior. Given the relevant words, it is a relatively simple matter to devise the appropriate rules generating the correct inflected and derived forms. It is not possible, however, to exactly predict, on purely morphotactic or phonotactic grounds, which words should undergo the alternation process. Consequently, it is not unlikely that Bulgarian speakers have all the relevant allomorphs of alternating words permanently stored in their internal lexicon.

The psycholinguistic literature presents contradicting evidence with respect to the issue of morphophonological complexity in Slavic languages. One major source of data is Serbo-Croatian, which has received some attention since Georgije Lukatela's influential research. In Lukatela et al. (1980), masculine and feminine nouns were examined in a lexical decision task. The nominative case of feminine nouns does not coincide with the root, in contrast to masculine nouns where baseform and root coincide. Despite this, the above nouns behaved exactly alike, showing that there is direct access of the nominative case (the base-form) irrespective of morphological structure. In a subsequent study, Lukatela et al. (1987) compared the lexical decision times of the nominative, dative/locative and instrumental cases. The dative/locative may involve some morphophonological complexity in a certain class of feminine nouns, where the shape of the root changes with respect to the nominative; the same happens with the instrumental in another feminine nouns

1. Other terms often appearing in the literature, alongside «floating», are «fleeting» and «ghost» vowels. One also finds reference to «alternating», «epenthetic», and even «fugitive», «movable» and «latent» vowels. 
class (cf. below for some examples). This irregularity pattern should best be regarded as a sort of «subregularity» within the lexicon, rather than sheer irregularity, because the morphophonological behaviour of these words is to some extent predictable. The results confirmed that the nominative (irrespective of morphological structure) has a clear advantage over the other cases, in accordance with the socalled «satellite model» proposed by Lukatela et al., while no difference was observed between the dative/locative and the instrumental, and no difference at all emerged between purely regular and subregular nouns. Feldman and Fowler (1987), however, again working on Serbo-Croatian, found a slightly different pattern of results. The materials in their experiment 3 consisted of nouns presenting morphophonological changes, namely: a) subregular feminine nouns (e.g., nom. noga 'leg', dat./loc. nozi; this is one of the types in Lukatela et al. 1987); b) masculine nouns presenting «vowel/consonant» alternations (e.g., nom. petao 'cock', dat./loc. petlu); c) masculine nouns presenting «vowel/ Ø» alternations (e.g., nom. petak 'Friday', dat./loc. petku). Interestingly, the latter alternation type is of the same kind as those that will be examined in the present paper. The results confirmed the nominative's privilege, irrespective of morphological structure, but also indicated that masculine and feminine nouns behave differently. In particular, among feminine nouns the instrumental (exhibiting no morphophonological change) was consistently faster than the dative/locative. Hence, in at least one instance, the declensional paradigm's morphophonological complexity seemed to have an effect on the lexical decision time.

Jetchev and Bertinetto (2000a, b), following the path inaugurated by Feldman (1994), addressed the issue of the opposition between so-called «perfective» vs. «imperfective» verbs, a well-known and debated topic in Slavic linguistics. In a repetition priming study, an inflectional process, based on person and number modifications, contrasted with one type of derivational process, concerning the derivation of imperfective verbs from perfective ones. Although no strong evidence for the contrast inflection vs. derivation (as exemplified in that particular study) was found, the two authors gathered evidence for the interaction between morphological and morphophonological complexity in one class of Bulgarian verbs, characterized by a high degree of unpredictability relative to the derivational process at stake. Slabakova (1999a, b) addressed the issue of the opposition perfective vs. imperfective from a different angle, analysing the semantic transparency of preverb-plusroot relation. Adjunction of a preverb (historically related to prepositions) is indeed the most frequent process involved in deriving perfective verbs from imperfective ones. She proved that Bulgarian speakers are sensitive: a) to the difference between semantically empty vs. semantically full preverbs; b) to preverb-plus-root compatibility, as depending on the actional value of the root (telic vs. stative). Finally, the study by Andonova et al. (2004) concerned gender processing in Bulgarian nouns, showing that factors such as phonological shape, word frequency, irregularity of gender marking, semantic gender (as reflected by concreteness, animacy and humanness) and finally — and quite predictably — grammatical gender, all have a bearing on the participants' speed and accuracy of gender decision. Surprisingly, the participant's sex also influenced the results to some extent. 
The present study aims at verifying whether Bulgarian vowel/ $\varnothing$ alternations, a morphophonological process also considered in Feldman and Fowler (1987), may prove to be a major factor for Bulgarian lexical access. In addition, we wanted to verify whether the interaction of the vowel alternation process with the morphological sub-domains of inflection and derivation would interfere with the output. To this effect, in experiment 1 we compared two types of $\varnothing$-forms: a) alternating nouns' plurals; b) abstract nouns derived from alternating adjectives. Finally, we considered the interaction of the vowel alternation process with two diverging stress patterns: stress on First vs. Second syllable. The reason for this is that in some Bulgarian alternating words the vowel that gets deleted in the plural is precisely the base-form's stress-bearing vowel.

\section{Experiment 1}

\subsection{Design and method}

Three classes of words were selected, each divided into two sub-classes, differing in terms of morphophonological complexity (non-alternating vs. alternating). Class A comprises nouns appearing in either masculine singular (the base) or plural form. The variation parameter is thus inflectional morphology. Bulgarian has a single plural form, irrespective of gender: there is no competition among different allomorphs, apart from a restricted number of irregular plurals. This regular and productive process lends itself as a natural candidate to illustrate a rule-governed morphological process. Class B also contains nouns appearing in either singular or plural form, but they differ from the previous ones in terms of stress structure. While A-words are stressed on the First syllable, B-words have stress on the Second syllable. In the case of the alternating sub-class B1, the morphophonological complexity of the plural is enhanced by the loss of the base-form's stressed vowel, namely its most prominent vowel, which supposedly makes root identification even more difficult. If there is any reason for Bulgarian speakers to directly access alternating words (rather than by rule), due to their complicated morphophonological structure, this sub-class is an obvious candidate. Finally, class $\mathrm{C}$ opposes adjectives in the masculine singular form (the base) and the corresponding abstract nouns, obtained by means of the suffix -ost. In this case, the relevant morphological parameter is derivation. Table 1 exhibits the materials' structure. Sub-classes marked by integer 1 contain alternating words, as opposed to non-alternating sub-classes indicated by integer 2. Each sub-class comprises 12 base elements, plus their respective morphological cognates (inflected forms in A and B, derived forms in C).

The alternation process works as follows. All words in sub-classes A1, B1, C1 build their plurals, or their derived cognates, by deleting the second vowel of the base-form, either /e/ or schwa. As noted above, in sub-class B1 the vowel that gets deleted in the plural is precisely the base-form's stressed vowel. This creates an opposition between sub-classes A1 vs. B1, although they both vary along the same morphological dimension (i.e. inflection, more specifically plural formation). By contrast, the words in Non-alternating sub-classes A2, B2, C2 preserve the base- 
Table 1. Characterizing features of the six sub-classes of experiment 1.

\begin{tabular}{llll}
\hline Sub-classes & Morphology & Stress & Alternation \\
\hline A1 & Inflection (plural) & First syllable & Alternating \\
\hline A2 & Inflection (plural) & First syllable & Non-Alternating \\
\hline B1 & Inflection (plural) & Second syllable & Alternating \\
\hline B2 & Inflection (plural) & Second syllable & Non-Alternating \\
\hline C1 & Derivation & First syllable & Alternating \\
\hline C2 & Derivation & First syllable & Non-Alternating \\
\hline
\end{tabular}

form's second vowel (any of the six Bulgarian vowel phonemes) also in inflection and derivation. As a result, words in A1, B1, C1 maintain the same number of syllables throughout, while words in A2, B2, C2 add one syllable in the inflected or derived forms. The added syllabic rhyme consists of the plural morpheme /i/ or the derivational morpheme /ost/, as appropriate. Here follows an example for each of the six sub-classes (Table 2).

Table 2. Examples of test words of experiment 1 (underlined characters indicate the stressed syllable).

\begin{tabular}{|c|c|c|}
\hline Sub-Classes & Base-form & Morphologically modified form \\
\hline A1 & fakel 'torch' & fakli 'torches' \\
\hline $\mathrm{A} 2$ & mebel 'piece of furniture' & 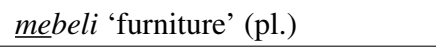 \\
\hline $\mathrm{B} 1$ & petel 'cock' & petli 'cocks' \\
\hline $\mathrm{B} 2$ & model 'model' & modeli 'models' \\
\hline $\mathrm{C} 1$ & dreven 'antique' & drevnost 'antiquity' \\
\hline $\mathrm{C} 2$ & pismen 'written' & pismenost 'writing' \\
\hline
\end{tabular}

Appendix A lists the whole set of materials. The list was arrived at by selecting the final set out of a much larger initial one, previously submitted to a native speakers' panel (composed of students in Sofia university) for subjective frequency evaluation. Participants expressed their judgment according to the following five-point scale:

$$
1=\text { very rare } \quad 2=\text { rare } 3=\text { in the average } 4=\text { frequent } 5=\text { very frequent }
$$

The rating procedure results, yielding perfectly balanced sets, are shown in Appendix A. Words with extreme values, in either direction, were discarded in order to avoid internal discrepancies. As for class $\mathrm{C}$, the scaling procedure concerned both the base and the derived word: once again, unbalanced pairs were avoided. ${ }^{2}$

2. The subjective frequency's method was selected due to lack of a sufficiently large frequency database. It is however a widely-admitted practice in experimental psycholinguistics, for the strict correlation of subjective and objective judgements has been experimentally proved. This method's 
The experimental paradigm was a repetition priming task with visual lexical decision. The task consisted of deciding, as fast as possible, whether the presented stimulus was a word or a non-word. Non-words, in the same number as words, were obtained by modifying a single consonantal phoneme of real words, chosen among those that were discarded after the rating procedure. Since non-words were obtained from words originally belonging to the same morphological paradigms as those used in the experiment, they too were subdivided into six sub-classes, formally corresponding to those described above (see table 1). This implies a very high density of the inflectional and derivational morphemes used in the experiment, thus enhancing the probability of triggering a decomposition procedure.

The primes consisted of the morphologically modified (inflected or derived) forms of each item (different condition) or of the corresponding base-forms (identical condition), with base-forms uniformly acting as targets, as shown in table 3 . For the sake of the discussion, we shall divide the targets into identical and «different» (i.e., «inflected» or «derived»), depending on whether they were preceded by an identical prime or by a morphological cognate. The reader should, however, be aware that all targets invariably consisted of base-forms. «Different» targets will be mentioned between quotes (distinguishing, when appropriate, between «inflected» and «derived») precisely to remind that they were not physically different from identical targets, but merely different with respect to the type of primes preceding them.

The prime/target distance was 10 words in the average, with a minimum of 8 and a maximum of 12 . Since participants could only see each target once, we com-

Table 3. Design of the experiment with regard to the factors Function and Condition.

\begin{tabular}{l|l|l}
\hline \multirow{2}{*}{ Function } & \multicolumn{2}{|c}{ Condition } \\
\cline { 2 - 3 } & Identical & Different \\
\hline Primes & base-form & inflected or derived form \\
\hline Targets & base-form & base-form \\
\hline
\end{tabular}

validity was also empirically demonstrated in experiments carried out in the SNS laboratory, where the results invariably showed a robust statistical opposition between subjectively frequent vs. subjectively rare words (Jetchev and Bertinetto 2000; Celata and Bertinetto forthcoming).

One caveat is in order, though. Our speakers were asked to provide their subjective judgments relative to the singular forms. This opens the possibility that the plural of some words might have yielded a different frequency rating. Unfortunately we are not in a position to control for this datum, although we have reasons to suppose that it could at most have played a minor role. That the plural's frequency might be a relevant factor, is shown by Baayen et al. (1996), who studied the different behavior of Italian «singular dominant» vs. «plural dominant» nouns, evidencing sharp discrepancies. While all singulars are responded to with the same speed (548 $\mathrm{ms}$ for «singular dominant» and $549 \mathrm{~ms}$ for «plural dominant» nouns), the plurals of plural dominant nouns are significantly faster than those of singular dominant nouns ( 533 vs. $573 \mathrm{~ms}$ ). This pattern, already assessed by Baayen et al. (1997) for Dutch, is confirmed by New et al. (2004) for French. These authors also provide a convincing explanation for the apparently deviant English pattern (see footnote 10). 
posed two balanced experimental lists, evenly distributing the various prime and target types. In the statistical analysis, we randomly paired each participant exposed to the first list with one participant exposed to the second list, thus obtaining, according to standard procedures, a set of «superparticipants».

There were 144 words, i.e. 72 base-forms and 72 morphologically modified ones (48 noun plurals and 24 abstract nouns derived from adjectives), plus an equal number of corresponding non-words: thus, altogether, 288 stimuli. Considering, however, that each item appeared in two conditions (Identical/Different), namely one condition per list, the total number of the experimental stimuli, words and nonwords together, raised to 576. For convenience, the 288 items of each experimental list were divided into two pseudo-randomized sub-lists of $144+6$ stimuli, consisting of: 72 words (36 primes and 36 targets, of which 18 in the Identical and 18 in the Different condition), 72 non-words (organized in the same way) and 6 fillers, words and non-words in the same proportion ( 2 at the beginning, to ensure a smooth start, and 4 towards the end, in order to maintain the minimum primes/target distance). Participants had a chance to pause between the two sub-lists.

The hardware consisted of a portable computer and a Superlab response box, developed by Hisham A. Abboud of Cedrus Corporation. The experiment program was taken care of by Maddalena Agonigi at the Laboratorio di Linguistica of Scuola Normale Superiore. Each participant was run individually, according to the following procedure. First, the experimenter read the instructions, and gave additional explanations if necessary. Then, after orienting the response box so that the YES button was on the side of the preferred hand, the participant was introduced to the training session (consisting of 12 stimuli). The training could be repeated on request. The presentation of each item was preceded by a warning sign and by the simultaneous appearance of a rectangular empty frame in the middle of the screen (in order to keep the fixation area stable), which remained visible for $500 \mathrm{~ms}$ before stimulus appearance. The item appeared right in the middle of the frame, and remained visible for $1000 \mathrm{~ms}$, after which there was a blank screen lasting 2000 $\mathrm{ms}$. When a slow response (more than $1000 \mathrm{~ms}$ ) was detected by the software, a warning appeared on the screen, prompting the participant to speed up her/his responses.

Experiment 1's factors were the following: Status (Word/Non-Word), FunCTION (Prime/Target), Condition (Different/Identical), MorPHOLOGY (Inflected/Derived), STRESS (First/Second syllable), ALTERnATION (Alternating/Non-Alternating). Morphology, Stress and Alternation were examined by opposing the relevant word classes according to the features exhibited in table 1, namely: Inflected vs. Derived $=$ A vs. C; First vs. Second syllable = A vs. B; Alternating vs. Non-Alternating = A1, B1, C1 vs. A2, B2, C2 (or relevant subsets, as appropriate). From now on we shall use capital initials to refer to specific sets within our materials (e.g., «Primes», «Different Primes», etc.), while we shall refrain from this when generically referring to these notions independently of this paper's experiments (e.g., «primes», «different primes», etc.). 


\subsection{An experimental control on the factor «length»}

Our design conceals a possible confound: morphologically complex items of Alternating vs. Non-Alternating sub-classes differ with respect to length, as measured in terms of syllables and graphemes/phonemes. This difference might obscure any statistical comparison.

In order to control for the length effect, a lexical decision control experiment was devised. We selected Bulgarian words exhibiting either one of the following structures: CVCCV (class 2/5: 2 syllables and 5 graphemes/phonemes) vs. CVCVCV (class 3/6: 3 syllables and 6 graphemes/phonemes). Note that Bulgarian orthography is fairly shallow, with virtually perfect graphemes to phonemes correspondence. All words were singular nouns stressed on the penult. This mirrors the situation of most relevant materials in our experimental set, as shown in Appendix A. The initial list was submitted to a native speakers panel for subjective frequency evaluation, according to the same procedure described in section 2.1. We selected 20 items in each class, with 2.60 vs. 2.61 as mean frequency ratings. In addition to these 40 words, we constructed an equal number of non-words, slightly modifying a number of discarded items of either type. The final random list, submitted for lexical decision to 20 native speakers (all students in Sofia university), was thus composed of 80 items.

The results were straightforward: the $t$-test comparison was non-significant. Interestingly, the average response time for class- $2 / 5$ words was slightly slower (686.60) than for class-3/6 words (675.05). Although the difference was non-significant, the tendency was not in favor of shorter words, as one might have expected. As it happens, the CV structure (namely, the prosodic-phonotactic composition) seems to matter more than the mere number of phonological units (syllables and phonemes). ${ }^{3}$

Since the structure of most Different Primes of sub-classes A1 and B1, as opposed to A2 and B2, is by and large the same as that in classes 2/5 vs. 3/6 (except for a few longer words), it appears that the results of experiment 1 can not possibly be biased by the supposed advantage of shorter words over longer ones. Indeed, as described below, the different average length was not directly reflected in the participants' reaction times (RTs).

\subsection{Participants}

The (paid) participants were 32, 16 in each list, all students in Sofia university and different from those who took part to the frequency rating tests or the control exper-

3. Rey et al. (1998) report a similar experiment, in which they compared RTs for 5-graphemes English words, containing a variable phonemes number. Interestingly, RTs were inversely proportional to phonemes number. These authors also report an identical outcome with French words, albeit limited to rare words. Although the type of materials in our experiment was different, for the number of graphemes was always identical to the number of phonemes, the trend is similar, in that the mere count of phonological units (syllables and phonemes) is not a reliable predictor of the participants' behavior. 
iment. Of these, two (one in each group) were discarded because of their unsatisfactory behavior. The statistical computations were thus based on 15 superparticipants. The threshold adopted consisted of the mean RTs \pm 2.5 the standard deviation value.

\subsection{Results}

We first eliminated all false responses. Next, following standard practice, we eliminated from further computations all targets relating to unrecognized primes, for in such cases the priming process was not properly activated. In all, we eliminated 334 observations out of 4032 (little more than 8\%), including both words and nonwords. No specific item appeared to cause an exceeding number of misses. The errors number was possibly increased by our decision to discard any response slower than $1000 \mathrm{~ms}$.

The next step was an ANOVA performed on the interactions between the factor List and all other factors. The general interaction proved to be vastly non-significant. The single individual interaction that turned out weakly significant was List $\mathrm{x}$ Condition. These results allow us to collapse the data into a single superlist. Our statistical computations were thus based, as anticipated, on 15 superparticipants, henceforth simply called participants.

We then performed a series of general ANOVAs on the main factors and their interactions. The factor Status (Word/Non-Word) was highly significant $(\operatorname{Pr}<.000)$ for all subsets of the materials. In the whole, Non-Words were $64 \mathrm{~ms}$ slower than Words (676.89 vs. 612.40). Equally, the factors Function (Prime/Target) and Condition (Different/Identical) were highly significant $(\operatorname{Pr}<.000)$, and so was the interaction Status $x$ Function. The advantage for Targets (collapsing Identical and «Different») over Primes was $26 \mathrm{~ms}$ with Non-Words, and $66 \mathrm{~ms}$ with Words. Thus, all basic effects predicted by the experimental method were consistently obtained.

We turn now to Words only. Given the structure of the experiment, the by-participants analysis (F1) is based on a «within» design, since each superparticipant reacts to all items; accordingly, we performed repeated measures ANOVAs. By contrast, the by-items analysis (F2) is based on a «between» design, so that univariate ANOVAs are in order.

In the errors analysis, the factor Function turns out to be very significant, while Alternation and Stress are fully significant by participants, and at most weakly significant by items ( $\mathrm{p}=.073$ and .076 , respectively). The factor Class is significant by participants while plainly non-significant by items, and so are the interactions Function x Morphology, Function x Stress, Class x Condition, Morphology x Condition. The interactions Function $\mathrm{x}$ Alternation and Class $\mathrm{x}$ Alternation, on the contrary, are significant in both analyses. Crucially, however, no «differential effect» (see below for explanation) emerges in the Identical vs. «Different» Targets comparison in any experimental subset. The error analysis yields, thus, a rather unrevealing picture.

Consider now the RTs analysis. Table 4 shows the mean values for Primes and Targets of all individual (sub)classes and their most relevant combinations. In the 
subset consisting of classes A and B, namely the subset relevant to the prosodic contrast First/Second syllable (in which one may disregard Morphology as irrelevant), all main factors are significant, although in the participants analysis Stress itself, i.e. the very contrast between classes $\mathrm{A}$ and $\mathrm{B}$, merely approaches significance $(\mathrm{F} 1(1,14)=.059)$. Alternation is only significant by participants $(\mathrm{F} 1(1$, $14)=.009)$ and plainly non-significant by items. No interaction turns out to be significant. We may thus conclude that the factor Stress is but weakly relevant: we shall return to this. With respect to the subset consisting of classes A and C, namely the subset relevant to the morphological contrast Inflected/Derived (where Stress was not at issue), the very factor Morphology, i.e. the contrast between classes A and $\mathrm{C}$ themselves, is non-significant, while all other main factors turn out significant, although in the participants analysis Alternation merely approaches significance $(\mathrm{F} 1(1,14)=.055)$. Again, no interaction turns out significant. Nevertheless, as the discussion will show (see section 2.5), the morphological contrast Inflected/Derived does yield some interesting effect in its interplay with Alternation.

The just quoted results involve a certain amount of noise, for Primes and Targets are jointly considered. Of crucial interest are thus the possible traces of a «differential priming» effect, to be gathered through the Function and Condition inter-

Table 4. Mean RTs for all individual (sub)classes and relevant combinations.

\begin{tabular}{|c|c|c|c|c|}
\hline & $\begin{array}{l}\text { Identical } \\
\text { Primes }\end{array}$ & $\begin{array}{l}\text { Different } \\
\text { Primes }\end{array}$ & $\begin{array}{l}\text { Identical } \\
\text { Targets }\end{array}$ & $\begin{array}{l}\text { «Different } \\
\text { Targets }\end{array}$ \\
\hline A & 653.86 & 664.26 & 573.47 & 590.82 \\
\hline $\mathrm{A} 1$ & 653.72 & 643.55 & 575.20 & 599.40 \\
\hline $\mathrm{A} 2$ & 654.01 & 685.52 & 571.60 & 582.01 \\
\hline $\mathrm{B}$ & 633.38 & 667.03 & 569.50 & 576.87 \\
\hline $\mathrm{B} 1$ & 619.06 & 663.33 & 559.16 & 580.55 \\
\hline B2 & 647.20 & 670.81 & 579.40 & 573.18 \\
\hline $\mathrm{C}$ & 651.93 & 652.36 & 584.76 & 604.14 \\
\hline $\mathrm{C} 1$ & 650.24 & 627.35 & 581.92 & 610.27 \\
\hline $\mathrm{C} 2$ & 653.72 & 681.01 & 587.68 & 596.96 \\
\hline$A+B$ & 643.46 & 665.69 & 571.46 & 583.61 \\
\hline $\mathrm{A} 1+\mathrm{B} 1$ & 636.75 & 653.69 & 567.30 & 589.70 \\
\hline $\mathrm{A} 2+\mathrm{B} 2$ & 650.43 & 677.95 & 575.69 & 577.42 \\
\hline$A+C$ & 652.90 & 658.14 & 579.07 & 597.67 \\
\hline $\mathrm{A} 1+\mathrm{C} 1$ & 652.01 & 635.01 & 578.48 & 605.16 \\
\hline $\mathrm{A} 2+\mathrm{C} 2$ & 653.87 & 683.26 & 579.69 & 589.43 \\
\hline$A+B+C$ & 646.24 & 661.15 & 575.80 & 590.55 \\
\hline $\mathrm{A} 1+\mathrm{B} 1+\mathrm{C} 1$ & 641.20 & 644.41 & 572.08 & 596.97 \\
\hline $\mathrm{A} 2+\mathrm{B} 2+\mathrm{C} 2$ & 651.50 & 678.95 & 579.59 & 583.70 \\
\hline
\end{tabular}


play. One wants to see whether the different prime type has a differential effect on the lexical decision's speed for Identical vs. «Different» Targets. Recall that Targets always consisted of the base-form (as shown in table 3): Identical and «Different» Targets simply means: "Preceded by the base-form itself (Identical) or by a morphological cognate («Different»)". In other words, since the two target types relating to a given noun or adjective invariably presented the same orthographic/phonemic form, any difference in the respective RTs should be entirely attributed to the priming effect. In detail, we want to check whether there is any advantage for Identical as opposed to «Different» Targets, with respect to the following contrasts: a) between Alternating (A1, B1, C1) vs. Non-Alternating sub-classes (A2, B2, C2); b) between the two stress patterns (classes A vs. B); c) between the different morphological structures (classes A vs. C). To this effect, one should consider all relevant materials subsets, namely the whole population $(A+B+C)$ as well as the individual (sub)classes or (sub)class combinations $(A+B$, opposing different stress patterns; $\mathrm{A}+\mathrm{C}$, opposing different morphological processes).

Table 5 presents the results in terms of mean RTs differences between «Different» vs. Identical Targets (cf. table 4 for the mean values). Asterisks indicate significant F1 and F2 contrasts. The presence of only one asterisk means that the participants analysis was the only one to reach significance. Asterisk between parentheses indicate marginal significance.

Let us first consider the mere contrast Identical vs. Different ignoring the Alternation factor, i.e. by collapsing Alternating and Non-Alternating items, as shown in the two upper sections of the table. The general trend to be observed is that there is a tendentially significant differential priming effect, although this effect is somewhat weaker in class $\mathrm{C}$ and non-existent in class $\mathrm{B}$. When, however, the factor Alternation is taken into consideration, as in the two lower sections, a sharp tendency emerges. As it happens, the differential effect is entirely due to the contribution of the Alternating sub-classes. In particular, when the behavior of the individual alternating sub-classes is separately examined, it turns out that the one exhibiting the strongest effect is $\mathrm{A} 1$, while $\mathrm{B} 1$ and $\mathrm{C} 1$ are only significant in the participants analysis. Our answer to point a) above is therefore that the Alternation factor heavily influences the advantage of Identical vs. «Different» Targets. As for point b), there clearly is an effect of prosodic structure, considering that class B behaves quite differently from A. Finally, as for point c), the different morphological process involved (inflection vs. derivation) also appears to have some effect on the behavior of the participants, although this emerges only through the interplay with Alternation. ${ }^{4}$

Summing up, the kind of morphological relatedness (plural formation vs. abstract noun formation) does not seem to tax in a significantly different way the amount of time needed for the lexical decision process, as shown in the analysis reported above for the factor Morphology, but morphophonological com-

4. In the errors analysis no differential effect emerged in any subset of the experimental materials. This, however, is hardly surprising, considering the relatively small errors number. 
Table 5. Advantages in ms and significance levels for various (sub)classes' combinations, expressed as RTs differences between «Different» vs. Identical Targets. Asterisks indicate significant F1 and F2 contrasts. Asterisks between parentheses indicate marginal significance.

\begin{tabular}{|c|c|c|c|c|c|c|}
\hline CLASSES $\rightarrow$ & \multirow{2}{*}{\multicolumn{2}{|c|}{$\begin{array}{c}\mathbf{A}+\mathbf{B}+\mathbf{C} \\
15^{* *} \\
\mathrm{~F} 1(1,14)<.000 \\
\mathrm{~F} 2(1,143)=.007\end{array}$}} & \multicolumn{2}{|c|}{$A+B$} & \multicolumn{2}{|c|}{$\mathrm{A}+\mathrm{C}$} \\
\hline $\begin{array}{l}\text { «ifferent» minus } \\
\text { Identical Targets }\end{array}$ & & & \multicolumn{2}{|c|}{$\begin{array}{c}12 * * \\
F 1(1,14)=.003 \\
F 2(1,95)=.044\end{array}$} & \multicolumn{2}{|c|}{$\begin{array}{c}18.5 * * \\
\text { F1 }(1,14)<.000 \\
\text { F2 }(1,95)=.005\end{array}$} \\
\hline $\begin{array}{l}\text { CLASSES } \rightarrow \\
\text { «Different» minus } \\
\text { Identical Targets }\end{array}$ & \multicolumn{2}{|c|}{$\begin{array}{c}17.5 * * \\
\mathrm{~F} 1(1,14)<.000 \\
\mathrm{~F} 2(1,47)=.040\end{array}$} & \multicolumn{2}{|c|}{$\begin{array}{c}7.5 \\
\text { F1 }(1,14) \text { n.s. } \\
\text { F2 }(1,47) \text { n.s. }\end{array}$} & \multicolumn{2}{|c|}{$\begin{array}{c}19.5 *(*) \\
\text { F1 }(1,14)=.015 \\
\text { F2 }(1,47)=.059\end{array}$} \\
\hline SUB-CLASSES $\rightarrow$ & $\begin{array}{l}\mathrm{A} 1+\mathrm{B} 1+\mathrm{C} 1 \\
\text { Alternating }\end{array}$ & $\begin{array}{l}\mathrm{A} 2+\mathrm{B} 2+\mathrm{C} 2 \\
\text { Non-altern. }\end{array}$ & $\begin{array}{c}\text { A1+B1 } \\
\text { Alternating }\end{array}$ & $\begin{array}{c}\mathrm{A} 2+\mathrm{B} 2 \\
\text { Non-altern. }\end{array}$ & $\begin{array}{c}\text { A1+C1 } \\
\text { Alternating }\end{array}$ & $\begin{array}{c}\mathrm{A} 2+\mathrm{C} 2 \\
\text { Non-altern. }\end{array}$ \\
\hline $\begin{array}{l}\text { «ifferent» minus } \\
\text { Identical Targets }\end{array}$ & $\begin{array}{c}25^{* *} \\
\text { F1 }(1,14)<.000 \\
\text { F2 }(1,70)=.004\end{array}$ & \begin{tabular}{|c|}
4 \\
F1 $(1,14)$ n.s. \\
F2 $(1,70)$ n.s. \\
\end{tabular} & $\begin{array}{c}22.5 * * \\
\text { F1 }(1,14)=.002 \\
\text { F2 }(1,46)=.0202\end{array}$ & $\begin{array}{c}2 \\
\text { F1 }(1,14) \text { n.s. } \\
\text { F2 }(1,46) \text { n.s. }\end{array}$ & $\begin{array}{c}26.5 * * \\
\text { F1 }(1,14)<.000 \\
\text { F2 }(1,46)=.007\end{array}$ & $\begin{array}{c}9.5 \\
\text { F1 }(1,14) \text { n.s. } \\
\text { F2 }(1,46) \text { n.s. }\end{array}$ \\
\hline SUB-CLASSES $\rightarrow$ & $\begin{array}{c}\text { A1 } \\
\text { Alternating }\end{array}$ & $\begin{array}{c}\text { A2 } \\
\text { Non-altern. }\end{array}$ & $\begin{array}{c}\text { B1 } \\
\text { Alternating }\end{array}$ & $\begin{array}{c}\text { B2 } \\
\text { Non-altern. }\end{array}$ & $\begin{array}{c}\text { C1 } \\
\text { Alternating }\end{array}$ & $\begin{array}{c}\mathrm{C} 2 \\
\text { Non-altern. }\end{array}$ \\
\hline $\begin{array}{l}\text { «ifferent» minus } \\
\text { Identical Targets }\end{array}$ & $\begin{array}{c}24 * * \\
\text { F1 }(1,14)=.002 \\
\text { F2 }(1,22)=.047\end{array}$ & \begin{tabular}{|c|}
10.5 \\
F1 $(1,14)$ n.s. \\
F2 $(1,22)$ n.s.
\end{tabular} & $\begin{array}{c}21.5 * \\
\text { F1 }(1,14)=.010 \\
\text { F2 }(1,22) \text { n.s. }\end{array}$ & $\begin{array}{c}-6 \\
\text { F1 }(1,14) \text { n.s. } \\
\text { F2 }(1,22) \text { n.s. }\end{array}$ & $\begin{array}{c}28.5 * \\
\text { F1 }(1,14)=.004 \\
\text { F2 }(1,22) \text { n.s. }\end{array}$ & $\begin{array}{c}9.5 \\
\text { F1 }(1,14) \text { n.s. } \\
\text { F2 }(1,22) \text { n.s. }\end{array}$ \\
\hline
\end{tabular}

plexity (in the form of vowel/Ø alternations) clearly does. Alternating vs. NonAlternating sub-classes yield a striking differential priming contrast. This also results in a relatively sharp interaction with Morphology. The «Different» Targets of the morphotactically transparent Non-Alternating sub-classes are equally affected by both type of morphologically modified Primes (inflected or derived). By contrast, the effect of the vowel alternation process on the morphotactically opaque Alternating sub-classes is enhanced by the purely morphological contrast inflected vs. derived.

\subsection{Discussion}

The design of experiment 1 aimed at evaluating the Bulgarian lexical access mechanism with respect to a number of variables. We contrasted:

a) Two different types of words, those exhibiting floating vowels vs. those immune from such a morphophonological complication;

b) Two different stress patterns, i.e. stress on the first vs. the second syllable;

c) Two different morphological processes, one in the domain of inflection (plural formation) vs. one in the domain of derivation (abstract noun formation). 
The statistical analyses show that the factor Morphology is non-significant, while Stress is but weakly significant. As for Alternation, it is non-significant within the whole population of data, and significant (or barely so) by participants within classes $\mathrm{A}+\mathrm{B}$ (contrasting as to Stress pattern) and $\mathrm{A}+\mathrm{C}$ (contrasting as to Morphology). The relevance of the factor Alternation, however, is best observed in terms of differential priming effects, i.e. in terms of RTs differences between Identical vs. «Different» Targets. From this point of view, the contrast Alternating vs. Non-Alternating appears to be fairly robust for most aggregations of data, as shown in table 5.

Let us try to disentangle the effects of the various factors (cf. table 4 for the mean values). Consider first Stress. The reason for including class B was that the dropped vowel in sub-class B1 plurals is precisely the base-form's stress-bearing vowel. We hypothesized that this mechanism could burden the speakers' mental processing. Interestingly, we did find an effect, but of an unexpected sort. As it happens, sub-class B1's Identical Primes are the fastest ones in the lexical decision procedure; all the remaining sub-classes yield practically the same RTs. ${ }^{5}$ Statistical analyses based on Student's test prove that this difference is significant, although only by participants, in all pair-wise comparisons of sub-class B1 vs. the remaining sub-classes. This seems to suggest that, in the Bulgarian speakers' mental lexicon, morphophonologically highly complex second-syllable-stressed words are especially prominent, as a result of their marked character. By this, we do not want to suggest that markedness necessarily entails fast lexical access, specially considering that marked patterns usually associate with low frequency. It is not unlikely, however, that fast access might occur in specific cases, for instance when a certain degree of morphophonological intricacy is attained, for idiosyncratically behaving words need to be directly accessed. ${ }^{6}$

Consider next Morphology, in its two manifestations: plural formation (classes $\mathrm{A}$ and $\mathrm{B}$ ) and abstract noun formation (class $\mathrm{C}$ ). In order to build a fair comparison, we specifically contrasted classes A vs. C, sharing the same stress pattern. No relevant difference was detected. On the one hand, Base Targets enjoy a significant advantage over «Inflected» Targets in both types of statistical analysis (F1 and F2); on the other hand, the analogous difference with respect to «Derived» Targets is fully significant in F1 and very close to significance in F2. This might

5. Note, however, that sub-class B1's Different Primes are the slowest ones to detect, as compared with $\mathrm{A} 1$ and $\mathrm{C} 1$ plurals. We do not have an explanation for this. We suspect that the overall frequency of these words' plurals might, on the average, be lower than that of sub-classes A1 and C1.

6. Stress position is in general unpredictable in Bulgarian, and inspection of Appendix A shows that there are no apparent phonotactic reasons for stress choice in our materials (compare mebel in class A2 and model in class B2). As far as disyllabic words are concerned, there has been a historical tendency in the Standard language (as opposed to the Western dialects) to stress the second syllable, but the productive Contemporary Bulgarian pattern, as reflected in loan-words adaptation, favors stress on the first syllable. Hence, in terms of potential productivity (see the Dynamic Morphology model exposed in Manova and Dressler 2001), sub-class B1 words constitute a doubly marked paradigm, with respect to both stress pattern and morphophonological behavior. 
be considered a welcome result for those who regard inflection and derivation as strictly comparable processes, regardless of whether they are based on rules or on direct access. No such conclusion is warranted by our data, however. Experiment 1 contrasted two specific processes in each of these morphological domains, rather than contrasting inflection and derivation in full scale. In particular, the kind of derivational process selected should not be taken as a prototypical representative of derivation, for it is based on a fairly regular and productive word-formation process. Besides, it works very similarly to the plural formation mechanism, for it also consists of adding a rhyme to the last consonant of the base. ${ }^{7}$ There is thus reason to believe that Bulgarian participants can easily derive abstract nouns in the same way as they produce noun plurals or, at any rate, that they can easily do so in an experimental setting like the one described, characterized by an unnatural density of this specific derivational affix. ${ }^{8}$ Indeed, given the virtual lack of fillers (except for the 6 comprised in each sub-list), the participants' behavior must have been driven towards the compositional strategy, irrespective of what happens in spontaneous situations. Consequently, although one might be inclined to believe that our data support the hypothesis that, generally speaking, there is no difference between inflection and derivation, we would suggest some caution, for at least four reasons. First, we only examined one particular derivational process. Second, this process appears to be very regular and productive, like most inflectional processes are. Third, the intimations of morphological compositionality must have been unnaturally biased by the experimental design. Forth, the contrast inflection vs. derivation was studied on two different words' sets (nouns in class A, adjectives in class C), so that the comparison was only indirect. Experiment 2 will tackle the last problem.

Turning finally to Alternation, i.e. to the specific morphophonological process under investigation, we observed a fairly sharp effect. The mean RTs advantage of Identical over «Different» Targets for the Non-Alternating items was $4 \mathrm{~ms}$, while the analogous advantage for the Alternating items was $25 \mathrm{~ms}$ (cf. the last two rows of table 4). There is thus, altogether, a $21 \mathrm{~ms}$ discrepancy between Alternating and Non-Alternating items. We may take this as a rough indication of the mental computation cost involved by Alternation. The computation cost was instead quite negligible for fully transparent words (particularly so in sub-class B2), for the amount of time needed for accessing the base-form, as primed by a morphological cognate or by itself, was essentially the same.

What does this mean? Does it mean that «Different» Targets of Alternating items are directly accessed with an extra time expenditure, or does it mean that the

7. The base-form of all words used in the experiment ended in a consonant. We shall return to this important detail in the general discussion.

8. It has been pointed out to us that the suffix -ost may be employed to build «action nouns», which (typologically speaking) often present a morphologically regular behavior. This, however, is not the case: class C's derived words are abstract nouns based on adjectives, rather than action nouns. The elicited behavior must be a property of the -ost class as such, independent of any specific semantic interpretation. 
activation of a specific vowel/ $\varnothing$ alternation rule needs an extra computational time? We have reasons to hypothesize that the former solution is the correct one. There are two hints to this. On the one hand, base-forms of morphophonologically complex words need some extra time to be accessed from their inflected or derived cognates, as shown by the differential priming effect described above. Ostensibly, when Bulgarian speakers access the Alternating items' modified forms, these do not automatically cause the activation of the corresponding roots, so that the priming effect is rather weak. The Alternating items' modified forms seem thus to behave, to some extent, independently of their base-forms. On the other hand, Alternating words as such, independently of the priming mechanism, appear to enjoy some kind of accessing advantage, as shown by their Primes' faster RTs as compared to Non-Alternating items. As one can gather from the last two rows of table 4, the mean advantage of Identical over Different Primes is a negligible $3 \mathrm{~ms}$ with Alternating items, but $27.5 \mathrm{~ms}$ with Non-Alternating ones. We interpret this as evidence of full listing, in the mental lexicon, of the Alternating items' morphologically modified forms, whose decision time turns out to be indistinguishable from that of the corresponding base-forms when no previous priming is involved (as is the case with primes). Needless to say, one should also take into consideration the different average length of Different Primes in Alternating vs. Non-alternating classes, as reported in Appendix A. Considering, however, the results of the control experiment reported in section 2.2, it is unlikely that this factor alone accounts for the RTs divergence.

The faster responses to the Different Primes of Alternating vs. Non-Alternating classes are quite remarkable. Statistical analyses based on Student $t$-test show that this contrast was significant, and so were the analogous comparisons between subclasses A1 vs. A2 and C1 vs. C2. Indeed, and quite strikingly, sub-classes A1 and C1 presented faster RTs to Different Primes than to Identical ones. This indicates that in some cases, characterized by a certain level of morphophonological complication, one may even observe faster decision times on morphologically modified forms than on the base-forms themselves. This is evidence that the former are directly accessed, rather than computed on-line. (As for Different Primes of sub-class B1, see footnote 5.)

Here is a possible explanation. If Non-Alternating and Alternating words could be distinguished by specific properties (e.g., phonotactics) which could set them apart from each other, we might expect that Bulgarian speakers would trigger a specific vowel/ $\varnothing$ alternation rule when activating the appropriate morphological process (plural formation or abstract noun formation). This is not the case. Compare the following words: bobar and gabər. There is no synchronic reason to suppose that they should behave differently, for they are virtually identical on phonotactic grounds; yet, the former belongs to sub-class A1 (Alternating), and the latter to sub-class A2 (Non-Alternating). Inspection of Appendix A provides other examples of this for all sub-classes, and further inspection into the Bulgarian lexicon would show that this happens in a non-negligible number of cases. Consequently, there would not be any real advantage in triggering a synchronic rule for the alternating words, since this would ultimately boil down to having idiosyncratic lexical 
marking for too many words. This would definitely look uneconomical. The alternative path, consisting of directly accessing the idiosyncratically alternating words in all their morphological variants, looks like the obvious solution, while compositionality remains available for non-alternating items. ${ }^{9}$ The attraction of this hypothesis, suggesting direct access for the morphologically modified forms of morphophonologically complex words only, is quite obvious on comparative grounds, considering that Baayen et al. (1997) noted a similar effect with some Dutch plurals. They observed evidence for full storage of inflected forms when parsing overcomes a certain degree of computational cost. Interestingly, the cost of parsing depended, among other factors, on the phonological and distributional properties of the plural suffix.

Summing up, the results of experiment 1 suggest that Bulgarian alternating words are directly accessed in both inflected and derived forms, as opposed to nonalternating words, which by contrast imply compositionality, i.e. rule-generation of their morphologically complex forms. As for the contrast inflection/derivation, its effect only emerges when enhanced by the alternation process. In addition, the base-forms of alternating final stress words (sub-class B1) enjoy a striking advantage in terms of lexical access, presumably as a result of their paradigm's marked character.

\section{Experiment 2}

\subsection{Introduction}

Despite the encouraging results of experiment 1, an objection might be raised. The inflected and derived items belonged to two different word classes: inflected words consisted of noun plurals (classes A and B), while derived words were abstract nouns built on adjectival bases (class C). This might have introduced some undesirable bias. For this reason, in experiment 2 we used a single word class, namely adjectives, from which one can build both inflected and derived forms.

\subsection{Design and method}

The materials consisted of two adjectives sets. Sub-class D1 comprised 12 adjectives presenting vowel/ $\varnothing$ alternations in both inflected (plural) and derived forms (abstract nouns formation). Sub-class D2, by contrast, included 12 adjectives presenting no alternation in either condition. The two morphological processes are the same as in experiment 1 . Table 6 provides an illustration.

9. Plural formation is the only inflectional process involved by Bulgarian nouns (unless one wants to consider the postponed article as a sort of inflectional marking), and one of the only two involved by adjectives, which are also declined for gender. Bulgarian speakers do not have to cope with a rich case system, as the speakers of other Slavic languages (cf. the Serbo-Croatian data quoted in section 1). It is thus quite likely that the plural of the relevant Bulgarian words is permanently stored in the mental lexicon. 
Table 6. Structure of experiment 2.

\begin{tabular}{llll}
\hline Sub-classes & $\begin{array}{l}\text { Base-forms (Targets } \\
\text { and Identical Primes) }\end{array}$ & Inflected Primes & Derived Primes \\
\hline D1 & hrabor 'brave, valiant' & plural: hrabri & derived noun: hrabrost \\
\hline D2 & iskren 'sincere' & plural: iskreni & derived noun: iskrenost \\
\hline
\end{tabular}

All words are stressed on the first syllable in any of the forms considered. As for the syllables' number, sub-class D1 forms are disyllabic, while inflected and derived forms of sub-class D2 are trisyllabic. Appendix B shows the materials' list, with the mean graphemic/phonemic length of each sub-class. It proved impossible to constrain the length difference to the very minimum: ideally, it should be of exactly one grapheme/phoneme, in practice it is almost two.

The final list was arrived at by selecting the materials out of a much larger initial set, submitted to native speakers (all students in Sofia university) for subjective frequency rating. The rating procedure is described in section 2.1; the results are shown in Appendix B. Words with extreme values (either very frequent or very rare) were discarded, in order to avoid unbalances. The rating procedure concerned both the base and the derived forms. Care was taken to avoid unbalanced pairs.

All experimental details are as in experiment 1, except that there was no need to split the factor Morphology into Morphology and Condition: namely, we did not need to distinguish Identical vs. Different (with Different corresponding to either Inflected or Derived). Morphology has thus three values: Base, Inflected, Derived: when convenient, we shall nevertheless use the notion «identity condition», referring to base-forms primed by themselves. All targets consisted of baseforms, while the corresponding morphologically modified forms (Inflected and Derived) or the base-forms themselves acted as primes. The targets designations as Base, «Inflected» and «Derived» (depending on the preceding prime) should be intended as purely conventional: the quotes in the last two target types hint at this.

All in all, there were 48 word items ( 24 base-forms and their morphological cognates), plus an equal number of non-words obtained in the same way as in experiment 1 . Once again, the unusual density of the relevant morphological affixes, exhibited by both words and non-words, might in principle have enhanced any tendency towards (de)compositional processing. Since each participant was supposed to respond only once to each target, we composed three balanced experimental lists, evenly distributing the corresponding prime types (Base/Inflected/Derived). In the statistical analysis, we randomly grouped participants from each list, obtaining a set of superparticipants. Each list comprised 102 items, namely: 48 Words (24 Primes, of which 8 Base, 8 Inflected and 8 Derived, plus their corresponding Targets), 48 Non-Words with the same distribution as Words, and 6 fillers (words and nonwords in the same proportion), two at the beginning and four at the end of the list. The Prime/Target distance was 10 words in the average, with a minimum of 8 and a maximum of 12 . The hardware and procedural details were as in experiment 1 , except for the cut-off threshold, that was fixed at $1200 \mathrm{~ms}$. 
The factors of the experimental design were: Status (Word/Non-Word), Function (Prime/Target), Morphology (Base/Inflected/Derived), Alternation (Alternating/Non-Alternating, i.e. sub-classes D1/D2). By-participants analyses consisted of repeated measures ANOVAs, for each superparticipant saw all Primes and Targets, while by-items analyses were based on univariate ANOVAs.

The hypotheses to be tested were the following:

a) Inflected and Derived Primes were expected to elicit slower target responses than Base Primes;

b) Derived Primes were expected to yield slower target responses than Inflected Primes;

c) Sub-class D1, presenting alternations, was expected to exhibit a larger differential priming effect than sub-class D2, meaning that «Derived» and/or «Inflected» Targets would suffer a significantly larger disadvantage as compared to Base Targets.

\subsection{Participants}

The participants were 51, 17 in each group, all students in Sofia university and different from those who had taken part to the subjective frequency rating. No participant had to be discarded due to unsatisfactory behavior. The criterion was based on the distance from the RTs mean (with 2.5 standard deviations as threshold).

\subsection{Results}

First, we checked for stimuli that were not correctly recognized, eliminating these data points from further computations, as well as any target associated to an unrecognised prime. We discarded 852 observations out of 5253, including both Words and Non-Words (namely $16.2 \%$, of which $11.6 \%$ were false responses and $4.6 \%$ correct responses associated to missed primes). No specific prime appeared to cause an exceeding number of misses. As for RTs, 3 primes exceeded the conventional threshold (the mean $\pm 2.5 \mathrm{SD}$ ), but they were all non-words.

An ANOVA was performed on the three experimental lists. No main factor or interaction proved to be significant in either analyses $(\mathrm{F} 1(2,607)=.189 ; \mathrm{F} 2(2$, $141)=.531$ ), which allowed us to collapse the data into a single superlist. Our statistical computations were thus based on 17 superparticipants, henceforth simply called participants.

The contrast Word/Non-Word was highly significant $(\operatorname{Pr}<.000$ in both analyses). Non-Words were almost 64 ms slower than Words (719.03 vs. 655.31). Equally, the contrast Prime/Target was highly significant $(\mathrm{Pr}<.000$ in both types of analysis). In other words, all basic effects predicted by the experimental paradigm were obtained.

Let us now turn to Words only. In the errors analysis, Function is the only significant factor: no interaction turns out significant. No differential effect emerges in the pair-wise comparisons between Base, Inflected and Derived Targets. The 
Table 7. Mean RTs for Primes and Targets in sub-classes D1 and D2.

\begin{tabular}{cccc}
\hline Primes & Base & Inflected & Derived \\
\hline D1 & 663.19 & 692.79 & 682.37 \\
\hline D2 & 685.11 & 719.66 & 728.64 \\
\hline TARGETS & Base & «Inflected» & «Derived» \\
\hline D1 & 600.15 & 626.88 & 636.08 \\
\hline D2 & 596.64 & 610.16 & 606.57 \\
\hline
\end{tabular}

errors analysis yields therefore a definitely flat picture, despite the far from negligible errors percentage.

As for RTs, the overall disadvantage for Primes over Targets is almost $83 \mathrm{~ms}$ (695.48 vs. 612.63). Sub-class D1 Primes were responded to some $31.5 \mathrm{~ms}$ faster than sub-class D2 Primes, as shown in table 7. This difference is consistent with the fact that sub-class D1 items are on the average shorter than sub-class D2 ones (see Appendix B). Nevertheless, although the length difference is larger in experiment 2 than in experiment 1, it is unlikely that the cited RT contrast can be explained by this detail. A difference in the same direction (about $22 \mathrm{~ms}$ ) emerges even with Base Primes, although sub-class D1 Base Primes are slightly longer than sub-class D2 ones. The observed difference cannot be attributed to a frequency unbalance, for the items of both classes were strictly matched for this parameter. It is thus more likely that the advantage of D1 items has the same origin as the analogous advantage observed in experiment 1, namely the special status of alternating words. Interestingly, with Base Targets any difference disappears, for sub-classes D1 and D2 yielded almost the same mean RTs. This is also reflected in the significant interaction Function $x$ Alternation $(\mathrm{F} 1(1,16)=.000 ; \mathrm{F} 2(1,140)=.003)$. On the other hand, the three-way interaction Function $x$ Alternation $x$ Morphology is non-significant.

The factor Morphology is highly significant by participants $(\mathrm{F} 1(2,32)<.000)$, but marginal to non-significant by items $(\mathrm{F} 2(2,141)=.079)$. This datum is hardly informative, however, for it collapses primes and targets. A much more revealing observation is that Base Targets (598 $\mathrm{ms}$ in the average) enjoy the predicted advantage over both «Inflected» and «Derived» ones, whose RTs are practically the same (618 vs. 621). This is consistent with point a) of section 3.2. As for point b), pair-wise comparisons are plainly non-significant with Inflected vs. Derived, and fully significant, or very close to full significance, with Base vs. Inflected (Primes: F1 $=.005 ; \mathrm{F} 2=.037$; Targets: F1 $=.021 ; \mathrm{F} 2=.058$ ); by contrast, the comparison Base vs. Derived is only significant by participants and marginal to non-significant by items (Primes: F1 $=.007 ; \mathrm{F} 2=.084$; Targets: $\mathrm{F} 1=.001 ; \mathrm{F} 2=.087$ ). The distance between Inflected and Derived items, and specifically Inflected and Derived Primes, is thus not huge, but the caveats put forward in section 2.5 apply once again. As a consequence, the answer to point b) can only be tentative. Nevertheless, there is ground to assume that in experiment 2 derivation produced stronger effects than inflection when combined with vowel alternation. 
Let us then consider point $\mathrm{c}$ ), relating to Alternation. The disaggregated means for Primes and Targets are shown in table 7. Pair-wise comparisons among the different Target types are systematically non-significant in sub-class D2, reiterating the situation observed in experiment 1 with the Non-Alternating classes. By contrast, in sub-class D1 the comparisons Base vs. «Derived» and Base vs. «Inflected» are significant by participants $(\mathrm{F} 1=.001$ and .035 , respectively) and very close to significance by items $(\mathrm{F} 2=.056$ and .055$)$, again approaching the situation in experiment 1 . These results encourage the conclusion that the presence, in D1 Primes, of the morphophonological complication at hand taxes the recovering of base-forms to an extent that is not observed in sub-class D2. In sub-class D1, the recognition of base-forms primed by their inflected or derived cognates is delayed, with respect to the identity condition, by about 26.5 and $36 \mathrm{~ms}$, depending on the morphological process involved, whereas the corresponding delays to be observed in subclass D2 are only 13.5 and $10 \mathrm{~ms}$, respectively. The difference between the two sub-classes emerges in particular with «Derived» Targets (i.e. base-forms primed by their derived cognates), showing that the combined effect of morphophonological (vowel alternation) and morphological intricacies (derivation, as opposed to inflection) yields a statistically sizeable effect. Indeed, the pair-wise comparison between D1 vs. D2 Targets is significant by participants $(\mathrm{F} 1=.024)$ and not remote from significance by items $(\mathrm{F} 2=.088)$ with «Derived» Targets, whereas it is definitely non-significant with Base and «Inflected» Targets. Besides, although the factor Function, i.e. the contrast Primes vs. Targets, is highly significant in every other subset of the experimental list (reaching at least $\operatorname{Pr}=.001$ for both F1 and F2), it is not fully significant (namely, significant only for F1) in the single comparison Derived Primes vs. «Derived» Targets of sub-class D1 $(\mathrm{F} 1=.005 ; \mathrm{F} 2=$ .076). Thus, altogether, Derived forms seem to behave differently with respect to Inflected ones.

\subsection{Discussion}

The design of experiment 2 was meant to verify the main results of experiment 1 . The specific variables taken into account were:

a) Alternation (a morphophonological process): we compared two different word types, with or without vowel/Ø alternation;

b) Morphology: we compared an inflectional process (plural formation) with a derivational one (abstract noun formation).

The statistical analyses show that, within the factor Morphology, the contrast Inflected/Derived is consistently non-significant. In this respect, the results of experiment 2 are even sharper than those of experiment 1 . This outcome, however, can hardly be taken as an indication that, generally speaking, inflection and derivation do not differ in terms of processing costs. See section 2.5 for elaboration on this issue. In addition, we gathered clear evidence that the latent contrast between these two morphological processes may emerge when their effects inter- 
twine with those of vowel alternation. With respect to the latter factor, experiment 2 essentially replicates experiment 1 , for sub-class D1, in contradistinction to D2, presents a robust differential priming effect.

\section{General discussion and conclusion}

The two experiments reported in this paper provide converging evidence with respect to the main variables at hand, namely the factors Alternation and Morphology. Since Stress was only studied in experiment 1, nothing will be added here to the conclusions pointed out in section 2.5. Suffice it to say that we found evidence that alternating words stressed on the second syllable (sub-class B1) enjoy a striking advantage in terms of access to their unprimed base-forms, presumably as a result of their peculiar morphophonological behavior, which sets them apart as an especially prominent lexical set.

Both experiments suggest that the inflected and derived forms of Bulgarian alternating words are directly accessed. By contrast, the corresponding forms of non-alternating words supposedly undergo the compositional treatment. The grounds for this claim are twofold. First, we observed a differential priming effect with alternating targets, as opposed to non-alternating ones. Second, we obtained faster RTs for the morphologically modified primes of alternating items, indicating the special lexical access status of this word type. Although theoretical phonology is not directly challenged by psycholinguistic experimentation, due to epistemological alterity, we believe that our data suggest an obvious conclusion as to the phonological treatment of Bulgarian floating vowels, historically related to Old Slavonic yers. The synchronic behavior of such vowels has been extensively morphologized and has thus become fairly unpredictable in its phonological manifestations, despite non-negligible areas of sub-regularity (Jetchev forthcoming). Any theoretical proposal concerning Bulgarian alternating words must take this into account. Our data suggest that the underlying representation of floating vowels should not overcome a certain degree of abstractness, since native speakers appear to by-pass any generative path relating to this morphophonological mechanism. They use instead the direct access path, indicating that the relevant words' morphologically modified forms are explicitly listed in the mental lexicon.

Although this conclusion sounds quite plausible, one problem suggests itself on comparative grounds. In a companion research concerning the behavior of Italian words with vs. without palatalization, Celata and Bertinetto (forthcoming) found that palatalizing and non-palatalizing words do not differ between themselves. By contrast, a differential priming effect emerged in a control set, conventionally named «non-velar», composed of items whose root does not end with a velar stop and hence lacks the very precondition for palatalization. The requirement consists, in Contemporary Italian, of the presence of $/ \mathrm{k} / \mathrm{or} / \mathrm{g} / \mathrm{in}$ root-final position, provided the relevant inflectional or derivational suffixes follow. Considered together, the results of the two parallel studies might appear surprising for the following reasons. First, in Bulgarian there is a differential priming contrast with alternating (morphotactically opaque) vs. non-alternating (transparent) words, whereas no sta- 
tistical difference emerges in the equivalent Italian case, namely in the opposition of palatalizing (opaque) vs. non-palatalizing (transparent) words. Second, the differential priming effect is observed in Bulgarian with the morphophonemically most complicated items (alternating words), whereas the effect emerges in Italian with the most transparent items, inherently immune from the palatalization process (non-velar words).

This seeming contradiction is probably explained, however, by the different situation in the two languages. All the Bulgarian words used in our two experiments end with a consonant, so that the base-form coincides with the root. In order to generate the plural or the derived noun, the appropriate suffix is simply added, whether or not the alternation process occurs. Note that this is not invariably the case, because a number of Bulgarian words have a base ending with a vowel which is replaced by another one in the plural (e.g., e.g., lice 'face' vs. lica 'faces', both stressed on the last syllable). Nevertheless, consonant-final words like the ones used in the present study are largely attested in the Bulgarian lexicon, and this constitutes a striking difference with respect to Italian, where consonant-final words are very rare, especially in the inherited lexicon. What one normally finds are vowel-final words, replacing such vowel in both inflection and derivation (e.g., tavol-o 'table', tavol-i 'tables', tavol-ata 'large laid table'; cas-a 'house', cas-e 'houses', cas-ata 'lineage'). This implies that the base-form of Italian words almost never coincides with the root, whereas this occurs quite frequently in Bulgarian and (most notably) it occurs in all items used in the present study.

Consider what happens when the participants to a priming experiment detect an inflected or derived form. With consonant-final Bulgarian items, provided no morphophonological complication is involved, participants necessarily access the root of the given word even when reading a morphologically modified form. The root's activation level is thus automatically raised, as if the base itself were presented. Consequently, no differential priming should be expected with fully transparent words, such as the Non-alternating ones. By contrast, with morphophonologically opaque words no full activation of the root should be expected, since its visual image cannot be detected and retained in the participants' memory. This is exactly what we obtained in our experiments. A very different picture obtains in Italian. When the participants detect the morphologically modified primes of transparent words (e.g., tavoli), they obviously see the root (e.g., tavol-) but not the corresponding base-form (tavolo). It is thus unsurprising that different and identical primes yield a differential impact on the targets, if the latter consist of the baseform. ${ }^{10}$

10. New et al. (2004) provide a similar explanation for the apparently diverging patterns of English — as opposed to Dutch, French and Italian — with respect to the processing of singular vs. plural forms. The relevant experiments contrasted singular-dominant and plural-dominant words, manipulating base- and surface-frequency. In Dutch, French and Italian there was no lexical decision time difference for singular forms, irrespective of dominance, whereas the plurals of plural-dominant words where responded to significantly faster than the corresponding forms of singular-dominant words. In English, on the contrary, singulars and plurals of plural-dominant words presented 
One might object that the proposed explanation does not account for the datum that Italian palatalizing and non-palatalizing words did not differ between themselves, although the latter words, in contrast to the former, are morphotactically transparent, just like the so-called non-velar words. One might expect that they should behave like non-velar items. This is not necessarily the case, however, for things are not actually equal on all counts. In particular, there is a remarkable difference at the graphematic level, because non-palatalizing words build their morphologically modified forms by adding the grapheme $<\mathrm{h}>$ after the velar consonant, to convey the information that they preserve the velar pronunciation, despite the presence of $/ \mathrm{i} /$ at the inflectional or derivational suffix's beginning. For instance, while the plural of amico [a'miko] 'friend' is amici [a'mit $\int \mathrm{i}$ ], the plural of fuco [fuko] 'drone' is fuchi [fuki]. This is ostensibly different from what one observes with non-velar words, where nothing else than the mere substitution of the desinence vowel occurs (tavolo $\sim$ tavoli). It is thus no wonder that the participants to Celata and Bertinetto's experiment yielded so strikingly different results for non-velar vs. velar-non-palatalizing words. The morphologically modified forms of non-velar words are clearly accessed through the activation of a straightforward desinence substitution rule, with detectable traces in terms of decision time. Indeed, there would not be any real advantage in directly accessing these forms, considering that they make up the great majority of the lexicon. By contrast, «velar» words (both palatalizing and non-palatalizing) are set apart as a fairly peculiar lexical set, whose morphophonological behavior is largely unpredictable, except for a few derivational affixes. Velar words are thus quite obviously available for direct access not only of the base-form, but also of the morphologically modified forms (inflected or derived).

Needless to say, further research is needed in order to shed full light on the matter. We would like to sketch two possible tests of the proposed explanation. The first would consist of reiterating the priming experiment, contrasting vowel-final vs. consonant-final transparent Bulgarian words. The prediction would be that the former items should behave more like non-velar Italian words than like the Non-alternating words used in experiments 1 and 2, possibly yielding a differential priming effect. Unfortunately, a parallel test concerning consonant-final Italian words is

very similar RTs while, crucially, the responses to singulars of plural-dominant words were significantly slower as compared to the analogous forms of singular-dominant words. In English, however, the base form is often ambiguous as to grammatical class, whenever it can be interpreted either as noun or as verb. Considering that the singular of plural-dominant words has a low surface-frequency, it follows that the lexical decision process is more likely to be inhibited by the alternative reading it has to compete with, namely the one corresponding to the homophonous verb form. By contrast, the high surface-frequency of the singular form of singular-dominant words does not suffer from this sort of inhibition.

This proves that cross-linguistic differences are a very powerful predictor of speakers' responses. In addition, it suggests analogy with the situation described in this paper. Just as Bulgarian presents, in most nouns, a systematic ambiguity between root and base-form (a feature displayed by English to an even higher degree), English presents a rather systematic root ambiguity between noun and verb. It is no wonder that the speakers' behavior mirrors these structural properties. 
impossible, considering that they are rare to non-existent in the inherited lexicon, and above all that they are normally excluded from inflectional and derivational processes. The second test would concern the inclusion of a control set in the Bulgarian materials, thus making the task more similar to the Italian one. Just as in Italian we had non-velar vs. velar words (with the latter further subdivided into velar-palatalizing and velar-non-palatalizing), in Bulgarian we could have alternation-free vs. alternation-bound words, with the latter ones further subdivided into alternating and non-alternating. Alternation-free words would consist of words containing vowels immune from alternation, whereas alternation-bound words would comprise words with the relevant vowels. The prediction would be that the alternation-free control set would approach the behavior of the analogous nonvelar set in the Italian experiment, inducing some kind of list-effect and possibly somewhat reducing the distance between alternating and non-alternating words.

\section{Appendix A}

Materials used in the experiment, with average subjective frequency ratings for each stimulus and sub-class. For sub-classes $\mathrm{C} 1$ and $\mathrm{C} 2$, the frequency ratings are separately provided for base-forms and derived words. The graphemic (and phonemic) length was obviously based on the Cyrillic alphabet rather than on the transliteration used in the text.

\begin{tabular}{llllll} 
A1: with vowel alternation & $\mathbf{3 . 1 7 5}$ & \multicolumn{2}{l}{ A2: without vowel alternation } & $\mathbf{3 . 1 6 1}$ \\
bobar & 'beaver' & 1.95 & mebel & 'piece of furniture' & 3.65 \\
vixar & 'whirlwind' & 2.1 & korab & 'ship' & 3.4 \\
filtar & 'filter' & 3.15 & gabar & 'pin' & 2 \\
negar & 'Black' & 3.6 & klamer & 'clip' & 3.35 \\
vopal & 'wail' & 2.25 & udar & 'strike' & 4 \\
chexal & 'slipper' & 3.75 & kufar & 'suitcase' & 3.7 \\
agal & 'corner' & 3.75 & svredel & 'auger' & 1.89 \\
kosam & 'strand of hair' & 4.25 & greben & 'comb' & 4.3 \\
lakat & 'elbow' & 3.5 & lebed & 'swan' & 2.65 \\
nokat & 'nail' & 3.9 & pudel & 'poodle' & 3.55 \\
vazel & 'knot' & 3.8 & storkel & 'stork' & 2.95 \\
fakel & 'torch' & 2.1 & daner & 'stump' & 2.5
\end{tabular}

mean graphemic/phonemic length of the base-forms:

5.0

5.41

mean graphemic/phonemic length of the inflected forms:

6.42

B1: with vowel alternation

petel 'cock'

kotel

'caldron'

orel

'eagle'
3.15

2.45

2.8
B2: without vowel alternation

2.35

2.42 


$\begin{array}{llllll}\text { oven } & \text { 'ram' } & 2.65 & \begin{array}{l}\text { fener } \\ \text { igrach }\end{array} & \text { 'lantern' } & \text { 'player' } \\ \text { strelec } & \text { 'archer' } & 2.9 & \text { sopol } & \text { 'snot' } & 4.05 \\ \text { pluvec } & \text { 'swimmer' } & 3 & \text { sopor } & 2.75 \\ \text { pevec } & \text { 'singer' } & 4.45 & \text { bodež } & \text { 'shooting pain' } & 2.25 \\ \text { lovec } & \text { 'hunter' } & 2.8 & \text { motor } & \text { 'motor' } & 3.95 \\ \text { telec } & \text { 'Taurus' } & 2.9 & \text { piron } & \text { 'nail, tack' } & 3.45 \\ \text { vdovec } & \text { 'widower' } & 2.65 & \text { imot } & \text { 'property, estate' } & 3.95 \\ \text { šturec } & \text { 'cricket (animal)' } & 2.58 & \text { zidar } & \text { 'mason' } & 2.45 \\ \text { konec } & \text { 'thread' } & 3.95 & \text { komar } & \text { 'mosquito' } & 3.9\end{array}$

mean graphemic/phonemic length of the base-forms:
5.33
4.91

mean graphemic/phonemic length of the inflected forms:

5.33

\begin{tabular}{|c|c|c|c|c|}
\hline C1 & base-form & 3.262 & & derived \\
\hline xrabor & 'brave' & 2.75 & xrabrost & 'bravery' \\
\hline štedor & 'generous' & 3.8 & štedrost & 'generosity' \\
\hline madar & 'wise' & 3.25 & madrost & 'wisdom' \\
\hline vedar & 'serene' & 2.65 & vedrost & 'serenity' \\
\hline podal & 'base' & 3.95 & podlost & 'baseness' \\
\hline nagal & 'arrogant' & 3.5 & naglost & 'arrogance' \\
\hline pošal & 'commonplace' & 1.95 & pošlost & 'commonplaceness' \\
\hline alchen & 'greedy' & 3.7 & alchnost & 'greed' \\
\hline skromen & 'modest' & 4.1 & skromnost & 'modesty' \\
\hline dreven & 'antique' & 3.15 & drevnost & 'antiquity' \\
\hline goden & 'valid' & 3.6 & godnost & 'validity' \\
\hline muden & 'sluggish' & 2.75 & mudnost & 'sluggishness' \\
\hline
\end{tabular}

3.116

2.8

3.25

3.3

2.55

3.35

3.5

2.25

3.45

3.55

3.2

3.95

2.35

\section{base + derived form: 3.189}

mean graphemic/phonemic length of the base-forms:

mean graphemic/phonemic length of the derived forms: $\quad 7.42$

\begin{tabular}{|c|c|c|c|c|c|}
\hline $\mathrm{C2}$ & base-form & $\mathbf{3 . 3 3 7}$ & & derived & 2.911 \\
\hline pargav & 'agile' & 2.9 & pargavost & 'agility' & 2.5 \\
\hline vesel & 'merry' & 4.3 & veselost & 'merriment' & 2.55 \\
\hline pismen & 'written' & 4.05 & pismenost & 'writing' & 3.35 \\
\hline predan & 'devoted' & 2.95 & predanost & 'devotion' & 2.9 \\
\hline trezven & 'sober' & 3.55 & trezvenost & 'sobriety' & 3 \\
\hline sobstven & 'own' & 4.35 & sobstvenost & 'property' & 4.8 \\
\hline žiznen & 'vital' & 3.65 & žiznenost & 'vitality' & 3.4 \\
\hline iskren & 'sincere' & 3.9 & iskrenost & 'sincerity' & 3.65 \\
\hline rumen & 'ruddy' & 2.45 & rumenost & 'ruddiness' & 1.79 \\
\hline gəvkav & 'supple' & 3.4 & gavkavost & 'suppleness' & 3.25 \\
\hline
\end{tabular}




\begin{tabular}{|c|c|c|c|}
\hline $\begin{array}{l}\text { nav } \\
\text { im }\end{array}$ & $\begin{array}{l}\text { 'clumsy' } \\
\text { 'meek' }\end{array}$ & $\begin{array}{l}3 \\
1.55\end{array}$ & $\begin{array}{l}\text { tromavost } \\
\text { xrisimost }\end{array}$ \\
\hline
\end{tabular}

\section{base + derived form: 3.124}

mean graphemic/phonemic length of the base-forms: $\quad 6.08$ mean graphemic/phonemic length of the derived forms: $\quad 9.01$

\section{Appendix B}

Materials used in the experiment, with average subjective frequency ratings for each word and corresponding derived form.

Base Der.

Base Der.

D1: with vowel alternation

\begin{tabular}{|c|c|c|c|c|c|c|c|}
\hline alčen & 'greedy' & 3.7 & 3.45 & gavkav & 'flexible' & 3.4 & 3.25 \\
\hline dreven & 'ancient' & 3.15 & 3.2 & hrisim & 'humble, meek' & 1.55 & 1.45 \\
\hline goden & 'fit, suitable' & 3.6 & 3.95 & iskren & 'sincere' & 3.9 & 3.65 \\
\hline hrabor & 'brave, valiant' & 2.75 & 2.8 & pargav & 'agile' & 2.9 & 2.5 \\
\hline madar & 'wise' & 3.25 & 3.3 & pismen & 'written' & 4.05 & 3.35 \\
\hline muden & 'slow, sluggish' & 2.75 & 2.35 & predan & 'devoted' & 2.95 & 2.9 \\
\hline nagal & 'insolent' & 3.5 & 3.4 & rumen & 'ruddy' & 2.45 & 1.79 \\
\hline podal & 'mean' & 3.95 & 3.35 & sobstven & 'one's own, proper' & 4.35 & 4.8 \\
\hline pošal & 'commonplace, trite' & 1.95 & 2.25 & trezven & 'sober' & 3.55 & 3.0 \\
\hline skromen & 'modest' & 4.1 & 3.55 & tromav & 'clumsy' & 3.0 & 2.3 \\
\hline štedor & 'generous' & 3.8 & 3.25 & vesel & 'cheerful, merry' & 3.6 & 4.1 \\
\hline vedar & 'bright, serene' & 2.65 & 2.55 & žiznen & 'vital' & 3.65 & 3.4 \\
\hline & & $\begin{array}{l}3.3_{3 .} \\
.\end{array}$ & & & & $\begin{array}{c}.26 \\
3.1\end{array}$ & \\
\hline
\end{tabular}

mean graphemic/phonemic length of the base-forms:

$5.41 \quad 6.08$

mean graphemic/phonemic length of the inflected forms:

5.41

7.08

mean graphemic/phonemic length of the derived forms:

7.41

9.08

\section{References}

Andonova, Elena; D’Amico, Simona; Devescovi, Antonella; Bates, Elizabeth (2004). «Gender and lexical access in Bulgarian». Perception \& Psychopsysics 66: 496-507.

Baayen, Harald; Burani, Cristina; Schreuder, Robert (1996). «Effects of semantic markedness in the processing of regular nominal singulars and plurals in Italian». 
In: Booij, Geert; van Marle, Jaap (eds.). Yearbook of Morphology 1996. Dordrecht: Kluwer, pp. 13-33.

Baayen, Harald; Dijkstra, Ton; Schreuder, Robert (1997). «Singulars and plurals in Dutch: Evidence for a parallel dual-route model». Journal of Memory and Language 37: 94-117.

Bertinetto, Pier Marco (1995). «Compositionality and non-compositionality in morphology». In: Dressler, Wolfgang U.; Burani, Cristina (eds.). Cross-Disciplinary Approaches to Morphology. Wien: Österreichische Akademie der Wissenschaften, pp. 9-36.

Celata, Chiara; Bertinetto, Pier Marco (forthcoming). «Lexical access in Italian: words with and without palatalization». Lingue e Linguaggio 2/2005.

Feldman, Laurie Beth (1994). «Beyond orthography and phonology: Differences between inflections and derivations». Journal of Memory and Language 33: 442-470.

Feldman, Laurie Beth; Fowler, Carol A. (1987). «The inflected noun system in SerboCroatian: Lexical representation of morphological structure». Memory \& Cognition 15: $1-12$.

Jetchev, Georgi (forthcoming). Ghost Vowels and Syllabification. Evidence from Bulgarian and French. Bloomington, Indiana: Slavica Publishers.

Jetchev, Georgi; Bertinetto, Pier Marco (2000a). «Lexical access in Bulgarian perfective vs. imperfective verbs». In: Benjaballah, Sabrina; Dressler, Wolfgang U.; Pfeiffer, Oskar E.; Voeikova, Maria D. (eds.). Morphology 2000. Selected Papers from the 9th Morphology Meeting. Vienna 24-28 February 2000. Amsterdam \& Philadelphia: Benjamins, pp. 161-173.

Jetchev, Georgi; Bertinetto, Pier Marco (2000b). «Lexical access in Bulgarian perfective vs. imperfective verbs (extended version)». Quaderni del Laboratorio di Linguistica della Scuola Normale Superiore 1, Nuova serie.

Lukatela, Georgije; Carello, Claudia; Turvey, Michael T. (1987). «Lexical representation of regular and irregular inflected nouns». Language and Cognitive Processes 2: 1-17.

Lukatela, Georgije; Gligorijevič, B.; Kostič, A.; Turvey, Michael T. (1980). «Representation of inflected nouns in the internal lexicon». Memory \& Cognition 8: 415-423.

Manova, Stela; Dressler, Wolfgang U. (2001). «Gender and declensional class in Bulgarian». Wiener Linguistische Gazette 67-69: 45-81.

New, Boris; Brysbaert, Marc; Segui, Juan; Ferrand, Ludovic; Rastle, Kathleen (2004). «The processing of singular and plural nouns in French and English». Journal of Memory and Language 51: 568-585.

Rey, Arnaud; Jacobs, Arthur M.; Schmidt-Weigend, Florian; Ziegler, Johannes C. (1998). «A phoneme effect in visual word recognition». Cognition 68: B71-B80.

Slabakova, Roumyana (1999a). «Aspectual constraints in the lexicon of Bulgarian speakers». CLASNET Working Papers 12: 2-14.

Slabakova, Roumyana (1999b). «Aspectual constraints in the mental lexicon». Journal of Psycholinguistic Research 30: 197-217. 